J. A. PRESCHER, D. H. DUBE, C. R. BERTOZZI* (UNIVERSITY OF CALIFORNIA, BERKELEY, USA)

Chemical Remodelling of Cell Surfaces in Living Animals

Nature 2004, 430, 873-877.

\section{Staudinger Ligation in Living Animals}

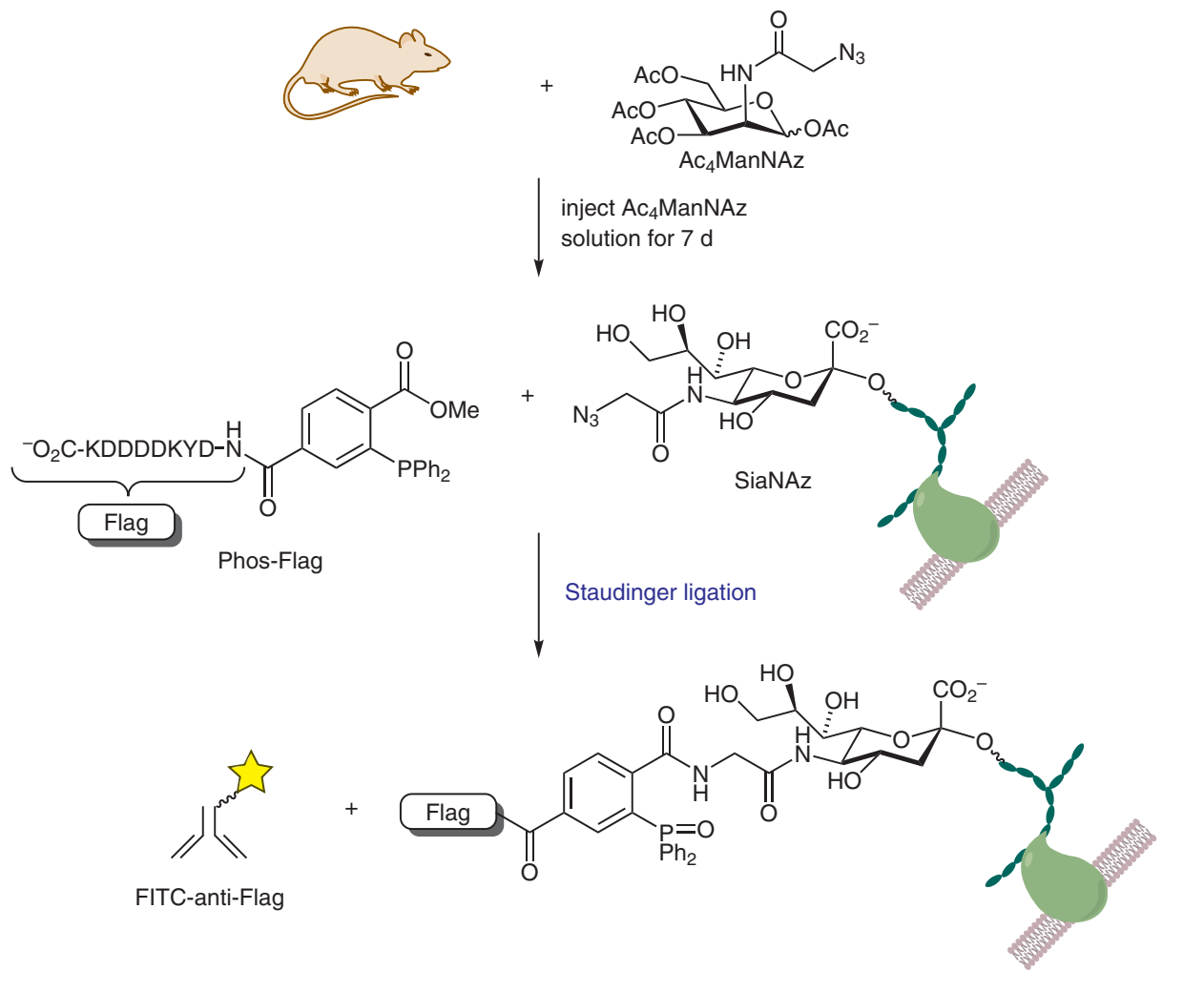

Staudinger ligation:
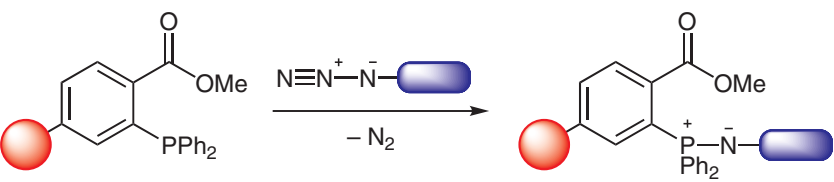

aza-ylide

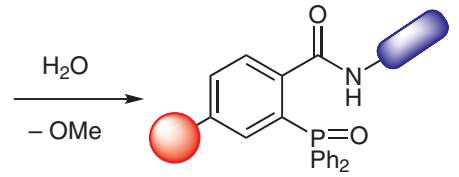

exogenous probe

endogenous sample

\title{
Category
}

Chemistry in

Medicine and

Biology

\section{Key words}

Staudinger ligation

metabolic

oligosaccharide

engineering

bioorthogonal

reaction

azides

phosphines

Significance: Chemical modification of cell-surface glycans in living animals provides a means to study these biopolymers within their native environment. The Staudinger ligation is a bioorthogonal reaction that can be carried out in the whole organism. This reaction is frequently used for the study of lipids, steroids, and cofactors.
Comment: Bertozzi and co-workers demonstrated the Staudinger ligation of an azide (SiaNAz) and a functionalized phosphine (Phos-Flag) in living mice. The azide was delivered to cell-surface glycoconjugates by metabolism of ManNAz to SiaNAz. The ligation in mice tissue was detected using fluorescein isothiocyanate-labelled anti-Flag antibodies followed by flow cytometry analysis. 